\title{
Effects of combined exercise on salivary oxidative stress in hypertensive and normotensive postmenopausal women
}

\author{
Ana Luiza Amaral ${ }^{1}$ (D), Igor Moraes Mariano ${ }^{1}$ (D), Jéssica Sanjulião Giolo ${ }^{1}$ (D), \\ Juliene Gonçalves Costa Dechichi ${ }^{1}$ (D), Adriele Vieira de Souza ${ }^{2}$ (D), Jaqueline Pontes Batista ${ }^{1}$ (D), \\ Tállita Cristina Ferreira de Souza ${ }^{1}$ (D), Douglas Carvalho Caixeta ${ }^{2}$ (D), \\ Leonardo Gomes Peixoto $^{2}$ (D), Renata Roland Teixeira ${ }^{2}$ (D), Foued Salmen Espindola ${ }^{2}$ (D), \\ Guilherme Morais Puga ${ }^{1}$ \\ ${ }^{1}$ Universidade Federal de Uberlândia, Laboratório de Fisiologia Cardiorrespiratória e \\ Metabólica, Uberlândia, MG, Brazil; ${ }^{2}$ Universidade Federal de Uberlândia, Instituto de \\ Biotecnologia, Laboratório de Bioquímica e Biologia Molecular, Uberlândia, MG, Brazil. \\ Associate Editor: Angelina Zanesco (D), ${ }^{1}$ Universidade Metropolitana de Santos, Faculdade de \\ Medicina, Santos, SP, Brazil; Universidade Estadual Paulista "Júlio de Mesquita Filho", \\ Departamento de Educação Física, Instituto de Biociências, Rio Claro, SP, Brazil. E-mail: \\ angelina.zanesco@unesp.br.
}

\begin{abstract}
Aim: This study evaluated the effects of 10 weeks of combined exercise training on the salivary oxidative profile of hypertensive and normotensive postmenopausal women. Methods: Twenty-six non-obese postmenopausal women were divided into two groups: the hypertensive group (HT; $\mathrm{n}=13 ; 58.9 \pm 3.9$ years; and BMI of $27.7 \pm$ $4.6 \mathrm{~kg} / \mathrm{m}^{2}$ ) or the normotensive group (NT; $\mathrm{n}=13 ; 52.7 \pm 5.2$ years; and BMI of $26.9 \pm 2.9 \mathrm{~kg} / \mathrm{m}^{2}$ ). They performed 30 sessions of combined exercises over 10 weeks: 45 min per session, three times a week. Resting saliva samples were collected after an overnight fast to evaluate salivary nitrite levels and oxidative stress markers before and after training.

Results: Two-way ANOVA showed that there was no difference in the responses over time between the hypertensive and normotensive groups in catalase, superoxide dismutase salivary activity, total antioxidant capacity, or lipid peroxidation. However, superoxide dismutase activity $(\Delta \mathrm{HT}-0.87 \pm 14.53 \mathrm{SOD} / \mathrm{mg}$ protein; $\Delta \mathrm{NT}$ : $7.13 \pm 9.39 \mathrm{SOD} / \mathrm{mg} \mathrm{pro}-$ tein; $\mathrm{p}<0.01)$ and nitrite levels $(\Delta \mathrm{HT} 10.32 \pm 60.83 \mathrm{mM} ; \Delta \mathrm{NT} 101.92 \pm 149.57 \mathrm{mM} ; \mathrm{p}=0.03)$ were higher overall in the hypertensive group compared to the normotensive group. Moreover, salivary nitrite levels increased over time $(p=0.04)$ in both groups. Conclusion: 10 weeks of combined exercise training did not change salivary oxidative stress markers in either normotensive or hypertensive postmenopausal women, although, after exercise training, nitrite levels increased in both groups, even with higher baseline salivary nitrite levels in hypertensive women. Thus, recurrent exercise seems to be a safe strategy after menopause from the standpoint of oxidative stress, regardless of the presence of hypertension.
\end{abstract}

Keywords: superoxide dismutase, nitrite, saliva, climacteric, combined exercise.

\section{Introduction}

Menopause is characterized by the cessation of estrogen production by the ovaries, resulting in permanent amenorrhea ${ }^{1}$. Additionally, estrogen is a cardioprotective hormone ${ }^{2}$ that plays a role in the modulation of endothelial function ${ }^{3}$. So, the lack of this hormone can lead to endothelial dysfunction and increase oxidative stress ${ }^{4}$ which may trigger cardiovascular diseases such as hypertension ${ }^{5}$. In this way, the imbalance between prooxidant and antioxidant factors leads to oxidative stress, causing cell damage ${ }^{6}$ due to excess reactive oxygen species (ROS) production ${ }^{6}$. Furthermore, oxidative stress may be accentuated by hypertension ${ }^{7}$ and cause deregulation of vascular tone control through changes in the bioavailability of nitric oxide $(\mathrm{NO})^{7}$, an endothelium-derived relaxing factor that promotes vasodilation ${ }^{7}$.

NO metabolism produces inorganic anions such as nitrate and nitrite, which are commonly evaluated in biological samples ${ }^{8}$. The main form of NO production is the L-arginine pathway, which occurs from NO synthase (NOS) isoforms, mainly by endothelial NOS, which can be produced by the vascular endothelium and is directly linked to the regulation of vascular tone and maintenance of endothelial integrity ${ }^{9}$. Oxidative stress caused by diseases associated with endothelium dysfunction can increase the activation of antioxidant enzymes, such as 
catalase and superoxide dismutase (SOD), in an attempt to maintain body homeostasis ${ }^{10}$. In this sense, assessment of antioxidant enzymes, total antioxidant capacity, and oxidative damage in saliva could provide alternative ways to find information about oxidative balance through less invasive methods than venipuncture.

Endothelial dysfunction and the lack of NO production that can be observed in post-menopausal women may lead to increased peripheral vascular resistance ${ }^{11}$, which facilitates the onset of hypertension. Non-pharmacological treatments such as physical exercise practice can have positive responses, improving both endothelial function ${ }^{12}$ and the antioxidant system ${ }^{13}$. In this sense, hypertension guidelines ${ }^{14,15}$ recommend the practice of moderate aerobic training and resistance exercise as support, since they can reduce resting blood pressure (BP) ${ }^{16}$ and improve oxidative balance ${ }^{17,18}$. However, only a few studies have investigated the effects of combined aerobic and resistance exercise training on oxidative stress, especially in saliva or in postmenopausal women. Furthermore, considering that these women have a higher prevalence of hypertension ${ }^{5}$, it is still unknown whether the presence of this disease generates any different response in oxidative stress markers compared to women without the disease when submitted to combined training. Therefore, this study aimed to assess the effects of 10 weeks of combined aerobic and resistance training in salivary oxidative stress markers in non-obese hypertensive and normotensive postmenopausal women. We hypothesized that hypertensive women would have worse oxidative balance and that combined exercise training would be able to improve both nitrite and the antioxidant system in both groups.

\section{Material and methods}

\section{Participants}

This was a parallel clinical trial study developed in two stages: before and after 10 weeks of combined exercise. Participants were divided into two groups: HT hypertensive $(\mathrm{n}=13)$ and NT normotensive $(\mathrm{n}=13)$. A total of 260 women, aged 50-70 years, were recruited from traditional media (TV, radio, and posters) and registered from January 2015 to December 2017 at the Laboratory of Car- diorespiratory and Metabolic Physiology of the Federal University of Uberlândia, Uberlândia, MG, Brazil; women were recruited at the same time as sample collection occurred. The inclusion criteria for the study were as follows: amenorrhea for at least 12 months, body mass index $\leq 32 \mathrm{~kg} / \mathrm{m}^{2}$, ability to engage in treadmill and resistance exercise training, without diabetes or cancer treatment, not undergoing dental treatment, no use of beta-blockers, no hormone therapy, non-smokers, and not using drugs that alter the lipid profile. To be included in the hypertension group, women had to self-report being hypertensive and using antihypertensive medication. The study design is presented in Figure 1. The Human Research Ethics Committee of the Federal University of Uberlandia approved this study (CAAE: 40622414.9.0000.5152). All the volunteers signed a consent form. The experiments were carried out in accordance with the principles set out in the World Medical Association Declaration of Helsinki. This study was registered at Clinicaltrials.gov (number: NCT03008785).

\section{Anthropometry evaluation}

The volunteers were instructed to maintain their regular diet. Their body mass was measured using an electronic scale (Micheletti, São Paulo, SP, Brazil), height was measured using a stadiometer (Sanny, São Paulo, SP, Brazil) and abdominal circumference was measured with an inelastic tape (Sanny, São Paulo, SP, Brazil) measuring $0.5 \mathrm{~cm}$ wide. A tetrapolar bioelectrical impedance analysis (Biodynamics model 450c, Biodynamics, Shoreline, WA, United States) was used to evaluate the total lean mass, fat mass, and percentage of total body fat. It was performed in the morning after at least eight hours of fasting, and hydration was controlled.

\section{Physical fitness assessment}

A short version of the International Physical Activity Questionnaire (IPAQ) ${ }^{19}$ was used to evaluate the initial physical activity level of the volunteers, classifying them as sedentary, irregularly active, active, or very active. The aerobic capacity assessment was determined through an incremental treadmill test adapted from previous study ${ }^{20}$. Briefly, all volunteers performed a submaximal incremental test on a treadmill at $5.5 \mathrm{~km} / \mathrm{h}$ and

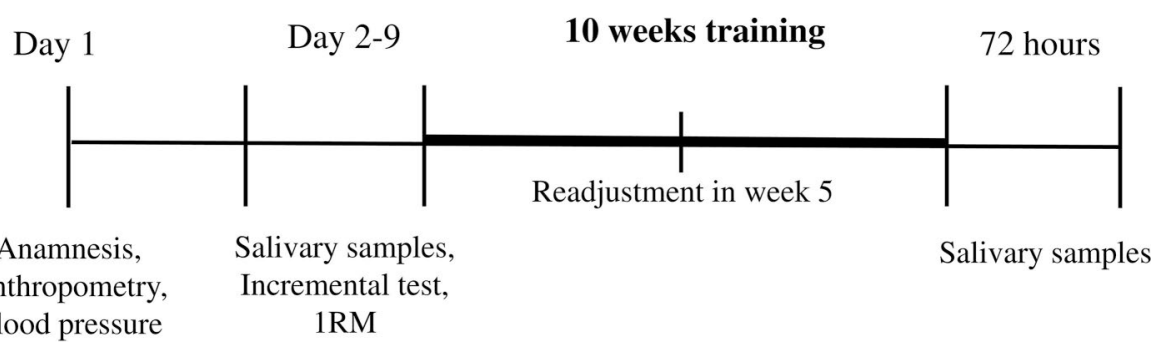

Figure 1 - Study design. 1RM: one maximum repetition test. 
the intensity was increased using only treadmill inclination ( $1 \%$ every two minutes) until the volunteers reached $85 \%$ of their predicted maximum heart rate (HR) or their rate of perceived exertion (RPE) reached 18 using the Borg scale. Oxygen uptake $\left(\mathrm{VO}_{2}\right)$ and carbon dioxide output $\left(\mathrm{VCO}_{2}\right)$ were recorded during all tests using a Cosmed Quark CPET gas analyzer (Rome, Italy). The goal of this test was to identify ventilatory thresholds $\left(\mathrm{VT}_{1}\right.$ and $\left.\mathrm{VT}_{2}\right)$ based on ventilatory equivalents for oxygen $\left(\mathrm{VE} / \mathrm{VO}_{2}\right.$ ratio) and carbon dioxide $\left(\mathrm{VE} / \mathrm{VCO}_{2}\right.$ ratio $)^{21}$. The intensity of resistance exercise was evaluated and prescribed based on a one-repetition maximum test $(1 \mathrm{RM})^{22}$, which happened once before and once in the fifth week of training in the following exercises: leg press $45^{\circ}$, seated low row, vertical chest press machine, pec deck, and wide grip lat pull-down. This test consisted of the workload performed with no more than one repetition in five tries with three minutes of rest between tries $^{22}$.

\section{Exercise program}

The exercise program consisted of 30 sessions of combined aerobic and resistance exercise training during 10 consecutive weeks (three sessions per week). Absences were made up on the nearest day when there were no sessions scheduled. Each session lasted $45 \mathrm{~min}$ and consisted of five min warm-up, $20 \mathrm{~min}$ of resistance exercise, and 20 min of aerobic exercise, with the order of the exercises alternated between sessions. After five weeks of training, the 1RM test was performed again to readjust the resistance training load. The aerobic intensity was readjusted with a $20 \%$ increase in inclination the same week. Resistance training was performed in two sets of 15 repetitions in seven weight training exercises (from a new 1RM test; we readjusted $60 \%$ of $1 \mathrm{RM}$ in the fifth week) for large muscle groups: leg press $45^{\circ}$, seated low row, vertical chest press machine, pec deck, wide grip lat pull-down, Swiss ball squat and abdominal crunch. The aerobic exercise was performed on a treadmill, at a speed of $5.5 \mathrm{~km} / \mathrm{h}$ and intensity (imposed by treadmill inclination and heart rate) between $\mathrm{VT}_{1}$ and $\mathrm{VT}_{2}$.

\section{Salivary analyses}

Saliva samples were collected after $12 \mathrm{~h}$ of fasting before the first and $72 \mathrm{~h}$ after the last exercise training session. All samples were kept frozen at $-80{ }^{\circ} \mathrm{C}$ until analysis and biochemical determinations were made in duplicate. Total antioxidant capacity was evaluated using the FRAP method and calculated from the standard Trolox curve ${ }^{23}$. The activity of SOD was determined based on the autooxidation capacity of pyrogallol and catalase by monitoring the consumption of hydrogen peroxide at $240 \mathrm{~nm}^{23}$. Lipid peroxidation levels were determined by the TBARS method, using as the standard a curve of 1,1,3,3-tetramethoxypropane ${ }^{24}$. The amounts of $\mathrm{NO}$ were estimated by the determination of total nitrite by the Griess colorimetric method $^{25}$.

\section{Statistical analysis}

The data are presented as mean \pm standard deviation. The data distribution was analyzed using the Shapiro-Wilk test, and non-parametric data were transformed until a normal distribution was achieved (log or z-score). The sample size was calculated by GPower 3.1.9.2, considering variations of $4 \pm 4 \mathrm{mM}$ in nitrite as acceptable for this population after a training program ${ }^{26}$, with an $\alpha$ value of 0.05 and power analysis of $85 \%$, resulting in 26 volunteers. An unpaired Student's t-test was applied to compare baseline groups and two-way analysis of variance (ANOVA) for repeated measures was used to analyze time (pre and post) and group (NT and HT) effects with a Bonferroni post hoc test, when appropriate. For outlier identification, the extreme studentized deviate method was used. Effect sizes (Hedges' g) are presented. A p-value of $<0.05$ was considered statistically significant, and all statistical analyses were performed using SPSS software version 20.0 (IBM, New York, NY, USA).

\section{Results}

Forty volunteers who fulfilled the inclusion criteria were recruited, and 14 volunteers were excluded: one modified their antihypertensive medication during the protocol, one sample analysis failed, two left due to health problems not related to the study, four did not complete for personal reasons, and six due to incompatible frequency or scheduling. So, 26 completed the 10 weeks of training and performed the post-tests. Figure 2 shows the flowchart.

Table 1 shows the anthropometric and general characteristics of all participants from both groups and the antihypertensive drugs used by the HT participants. HT subjects were older $(\mathrm{p}=0.01)$ when compared to NT $(58.9 \pm 3.9$ years for HT and $52.7 \pm 5.2$ years for NT). There were no significant differences in other variables between groups.

Table 2 shows the salivary oxidative stress marker levels, analyzed (ANOVA two-way) before and after the 10 -week intervention in both groups. There were no interaction effects (group * time) in nitrite, catalase, FRAP, SOD, and TBARS. SOD levels were lower $(\mathrm{p}<0.01)$ in NT at both the pre- and post-time points. Two-way ANOVA showed that nitrite values increased (pre vs. post) $(\mathrm{p}<0.01)$ in both hypertensive (pre: $87.6 \pm 44.0$; post $98.0 \pm 47.2 \mathrm{mM}$ ) and normotensive (pre: $50.2 \pm 28.6$; post $152.2 \pm 146.5 \mathrm{mM})$ groups with no difference between groups $(\mathrm{p}=0.16)$. 


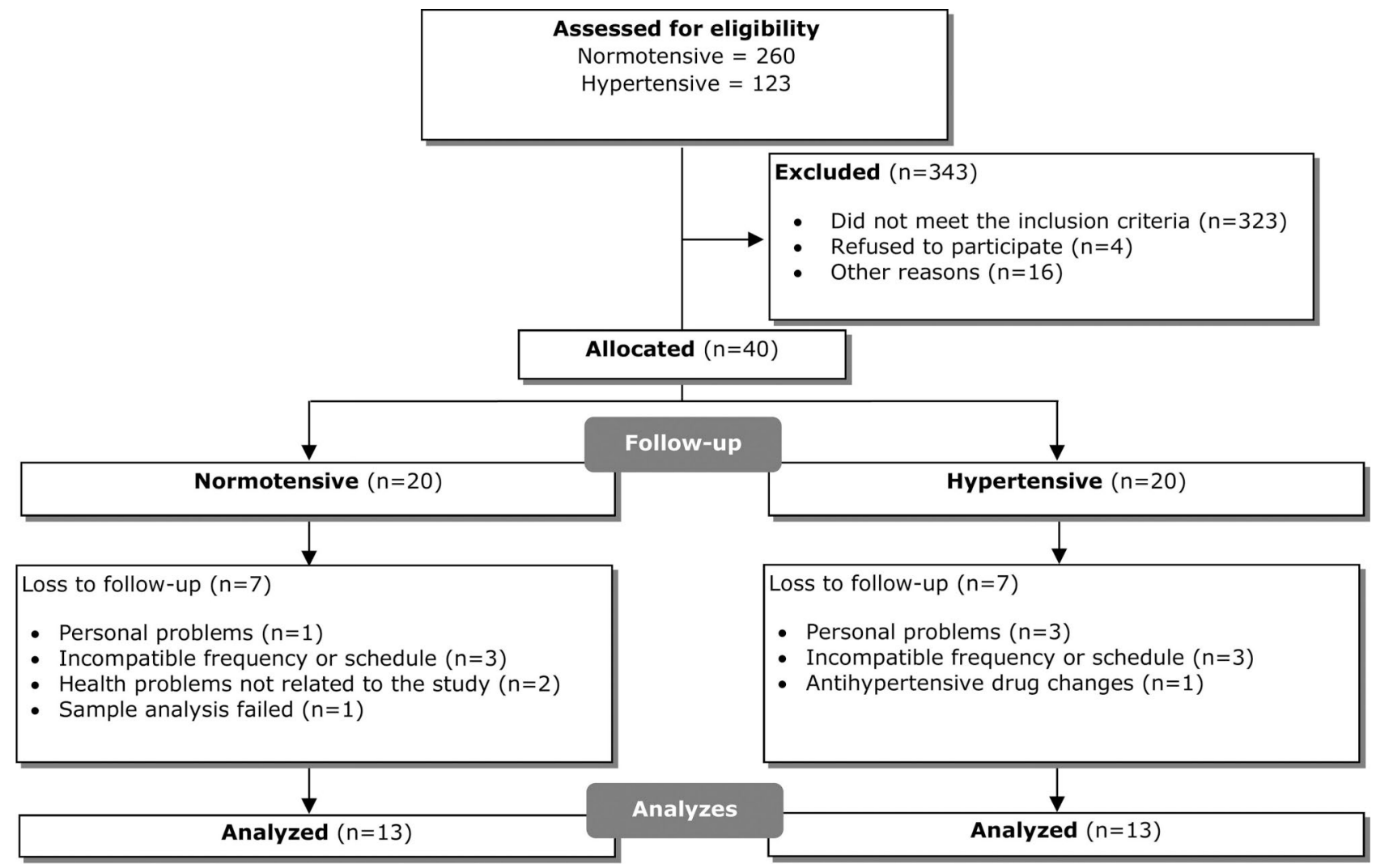

Figure 2 - Flowchart.

Table 1 - Volunteers characteristics.

\begin{tabular}{|c|c|c|c|}
\hline & NT $(n=13)$ & HT $(n=13)$ & $\mathbf{p}$ \\
\hline Age (years) & $52.7 \pm 5.2$ & $58.9 \pm 3.9$ & 0.01 \\
\hline Body mass (kg) & $64.8 \pm 9.0$ & $68.5 \pm 8.3$ & 0.29 \\
\hline BMI $\left(\mathrm{kg} / \mathrm{m}^{2}\right)$ & $26.9 \pm 2.9$ & $27.7 \pm 4.6$ & 0.60 \\
\hline Abdominal circumference $(\mathrm{cm})$ & $92.9 \pm 7.9$ & $93.6 \pm 9.2$ & 0.84 \\
\hline Body fat (\%) & $35.4 \pm 3.7$ & $38.4 \pm 7.0$ & 0.18 \\
\hline Fat mass (kg) & $23.0 \pm 4.6$ & $26.5 \pm 6.9$ & 0.14 \\
\hline Lean mass (kg) & $41.6 \pm 4.0$ & $39.2 \pm 4.0$ & 0.14 \\
\hline $\begin{array}{l}\text { Resting systolic blood pressure } \\
(\mathrm{mm} \mathrm{Hg})\end{array}$ & $129.1 \pm 17.4$ & $121.9 \pm 13.6$ & 0.25 \\
\hline $\begin{array}{l}\text { Resting diastolic blood pressure } \\
(\mathrm{mm} \mathrm{Hg})\end{array}$ & $84.3 \pm 12.2$ & $76.1 \pm 8.1$ & 0.06 \\
\hline \multicolumn{4}{|l|}{ Antihypertensive drugs - (n (\%)) } \\
\hline $\mathrm{ACE}$ & - & $2(15.4)$ & \\
\hline $\mathrm{AT}_{1}$ & - & $4(30.8)$ & \\
\hline Thiazide diuretics & - & $2(15.4)$ & \\
\hline $\mathrm{ACE}+$ Thiazide diuretics & - & $1(7.7)$ & \\
\hline $\mathrm{AT}_{1}+$ Thiazide diuretics & - & $4(30.8)$ & \\
\hline
\end{tabular}

Data are present in mean \pm standard deviation or $n(\%)$. NT: normotensive group; HT: hypertensive group; BMI: body mass index. ACE: angiotensinconverting-enzyme inhibitors; AT1: angiotensin II type 1 receptor blocker. 
Table 2 - Salivary oxidative stress markers in HT and NT before and after intervention.

\begin{tabular}{|c|c|c|c|c|c|c|c|c|}
\hline & \multirow{2}{*}{$\begin{array}{c}\text { Pre } \\
\text { Mean } \pm \text { SD }\end{array}$} & \multirow{2}{*}{$\begin{array}{c}\text { Post } \\
\text { Mean } \pm \text { SD }\end{array}$} & \multirow[t]{2}{*}{$\Delta$} & \multicolumn{3}{|c|}{$A N O V A$} & \multirow[t]{2}{*}{ Effect size } & \multirow{2}{*}{$\frac{t \text { test } p}{\text { Baseline }}$} \\
\hline & & & & p group & p time & $p$ interaction & & \\
\hline \multicolumn{9}{|c|}{ Nitrite (mM) } \\
\hline NT & $50.25 \pm 28.62$ & $152.16 \pm 146.51$ & $101.92 \pm 149.57$ & 0.16 & 0.04 & 0.07 & -0.97 & 0.03 \\
\hline HT & $87.64 \pm 43.98$ & $97.96 \pm 47.24$ & $10.32 \pm 60.83$ & & & & -0.23 & \\
\hline \multicolumn{9}{|c|}{ Catalase (U/mg prot) } \\
\hline NT & $15.51 \pm 7.23$ & $15.15 \pm 7.38$ & $-0.36 \pm 5.72$ & 0.20 & 0.74 & 0.25 & 0.05 & 0.32 \\
\hline HT & $20.38 \pm 15.20$ & $17.31 \pm 11.16$ & $-3.07 \pm 15.11$ & & & & 0.23 & \\
\hline \multicolumn{9}{|c|}{ FRAP (umol/L eq. Trolox) } \\
\hline NT & $59.62 \pm 43.82$ & $57.09 \pm 44.97$ & $-2.34 \pm 55.68$ & 0.09 & 0.81 & 0.93 & 0.06 & 0.66 \\
\hline HT & $53.28 \pm 22.97$ & $52.24 \pm 25.65$ & $-1.04 \pm 27.32$ & & & & 0.04 & \\
\hline \multicolumn{9}{|c|}{ SOD (SOD/mg prot) } \\
\hline NT & $3.30 \pm 0.82$ & $11.85 \pm 10.04$ & $7.13 \pm 9.39$ & $<0.001$ & 0.38 & 0.36 & -1.20 & $<0.001$ \\
\hline HT & $23.23 \pm 12.37$ & $22.36 \pm 17.78$ & $-0.87 \pm 14.53$ & & & & 0.06 & \\
\hline \multicolumn{9}{|c|}{ TBARS (umol/L) } \\
\hline NT & $5.12 \pm 1.17$ & $5.80 \pm 1.69$ & $0.69 \pm 1.65$ & 0.67 & 0.13 & 0.12 & -0.47 & 0.26 \\
\hline HT & $4.58 \pm 1.19$ & $4.90 \pm 1.09$ & $0.32 \pm 1.51$ & & & & -0.28 & \\
\hline
\end{tabular}

Data are present in mean \pm standard deviation. NT: normotensive group; HT: hypertension group; FRAP: ferric reducing ability of plasma; SOD: superoxide dismutase; TBARS: thiobarbituric acid reactive substances; $\Delta$ : Values of salivary variation (post - pre values).

\section{Discussion}

The present study investigated if 10 weeks of combined exercise could provide different responses in salivary oxidative stress between hypertensive and normotensive non-obese postmenopausal women. First, we found that women in the HT group were a little older than NT subjects, but they were all in the same age group as postmenopausal women and not yet elderly. In the oxidative stress variables, our results showed no differences in these markers between groups, although SOD activity was higher at baseline for the HT group. Moreover, salivary nitrite levels increased in both the HT and NT groups after exercise training, even with higher baseline levels in the HT group.

The hypertensive population had greater cardiovascular risk and worse vascular health ${ }^{27,28}$, mainly due to endothelial dysfunction ${ }^{11}$ involved in the production and action of substances related to BP control, such as relaxation factors (e.g. NO) ${ }^{9}$. The oxidative stress caused by this high BP can chronically intensify endothelial dysfunction ${ }^{7}$, lipid peroxidation, and inflammation ${ }^{7}$. Furthermore, oxidative stress may compromise other organs and systems that play a key role in the regulation of BP, such as the kidneys ${ }^{14,29}$, where activation of the renin-angiotensin-aldosterone system causes oxidative imbalance via NADPH-oxidase and decreased availability of NO and antioxidant enzymes ${ }^{29}$.

Some studies have found lower oxidative stress in healthy compared with hypertensive patients; while ROS production plays an important role in the development of hypertension, chronic moderate-intensity exercise training has been documented to ameliorate these ROS levels ${ }^{18}$. Unlike these results, we did not find improvements in salivary oxidative stress markers after exercise training in these women, but we believe that some factors were important in determining our results, such as BP levels and exercise training duration. In a previous study, we found that there were no significant differences in 24-h ambulatory blood pressure values between group ${ }^{30}$. These data also showed no undiagnosed hypertensive women from the outpatient examination. Furthermore, the hypertensive women in our study had been under antihypertensive drug treatment for more than three years, so they were treated, well-controlled hypertensive patients. Blood pressure levels are positively correlated with markers of oxidative stress and negatively correlated with antioxidant capacity ${ }^{18}$, so we believe that good regulation of BP levels in hypertensive women may attenuate oxidative stress markers over time. Another important factor was that we used a combined aerobic and resistance exercise training intervention for 10 weeks; this may have been too short a period to see differences in salivary oxidative stress markers in our volunteers.

The effects of physical training on oxidative balance in patients with hypertension are not unequivocal. Dantas et al $^{31}$ found improvements in plasma oxidative balance and nitrite levels in patients similar to those taking part in the present study (elderly hypertensive women) after 10 weeks of resistance training. A further study in hypertensive patients suggested that isometric handgrip training protected against plasma oxidative stress at rest and after 
exercise $^{32}$. However, as in the present results, no improvements in nitrite or lipid peroxidation were found. Lastly, Feairheller et al. ${ }^{33}$ demonstrated that six months of moderate-intensity aerobic exercises with 94 hypertensive and prehypertensive adults was sufficient to improve the plasma and urinary oxidative profiles, independent of the analyzed polymorphisms.

Similar to our results, some studies have also found no changes in oxidative stress markers after exercise training. Jarrete et al. ${ }^{34}$ showed higher SOD activity but did not find changes in the plasma levels of catalase or TBARS in hypertensive postmenopausal women after eight weeks of aerobic exercise training. Plasma oxidative stress markers (ex. SOD, catalase, glutathione peroxidase, and total antioxidant status) were also not different after 12 weeks nor 10 weeks of combined exercise training in women of the same age ${ }^{35,36}$. So, although our hypothesis was that exercise training could improve oxidative stress markers, and, in accordance with the literature, exercise training tends to improve antioxidant markers and decrease pro-oxidant markers, the intensity, volume, type of exercise, and type of population may directly influence these results ${ }^{37}$. It is worth mentioning that most studies use plasma analysis, and although saliva analysis is advantageous due to its ease of collection, there are still few studies that use it for their main analysis.

Another important point was that $84.7 \%$ of the HT group in our sample used drugs that act on the reninangiotensin system. It has been reported that AT1 receptor antagonists or angiotensin-converting enzyme inhibitors inhibit vascular remodeling and reduce ROS, not only by the reduction of NADPH oxidase but also by the positive regulation of $\mathrm{Cu} / \mathrm{ZnSOD}^{38}$. In addition, these drugs also partially improve endothelial function regardless of BP reduction $^{39}$. These antioxidant actions are important because oxidative stress and $\mathrm{NO}$ elimination due to excess ROS are a major cause of reduced NO bioavailability ${ }^{39}$. Therefore, this result leads us to hypothesize that endothelial dysfunction, vascular remodeling, and increased lipid peroxidation in women after menopause ${ }^{40}$ reduces the bioavailability of $\mathrm{NO}$ and generates the need for increased SOD activity in both groups. Nevertheless, within the HT group in the present study, this was corrected by antihypertensive drugs.

Regarding the increase in NO expression after training, we know that during exercise there is an overproduction of ROS due to increased endothelial shear stress and mitochondrial respiratory chain inefficiency ${ }^{18}$. However, this acute momentary increase in oxidative stress possibly signals positive chronic antioxidant upregulation, providing long-term antioxidant capacity ${ }^{18}$. Despite some inconsistent results, some literature reviews ${ }^{13,17,18}$ seem to indicate positive oxidative balance effects of regular exercise. However, in relation to these parameters, it is worth mentioning that: 1) few studies have evaluated the chronic effects of exercise; 2) fewer studies are completed with hypertensive subjects; 3) almost all studies use aerobic exercise and 4) the influence of exercise load variables (i.e. intensity, volume, frequency) is still not very clear.

In this way, a clinical study with hypertensive women after menopause who underwent aerobic training for eight weeks (three days/week) showed higher plasma NO levels after training ${ }^{34}$. A meta-analysis ${ }^{41}$ on the effects of high-intensity interval training in patients with lifestyleinduced cardiovascular problems found a greater availability of NO and less oxidative stress when compared to lower intensity training. However, in general terms, moderate-intensity aerobic exercise is recommended, especially in populations more vulnerable to mechanical injuries, such as middle-aged and elderly people ${ }^{17}$.

To our knowledge, this is the first study to evaluate the relationship between combined training and salivary markers of oxidative stress in humans, especially in hypertensive patients. However, the present study has some limitations, such as the duration of the exercise training and the fact that BP was well-controlled by antihypertensive drugs in the HT group. Additionally, analyses comparing the classes of antihypertensive agents and the various characteristics of training load control (such as volume, frequency, and intensity) should be completed with this population on salivary oxidative markers in future studies. Thus, the results suggest that combined exercise at moderate intensity may be a good strategy to maintain vascular health and to improve NO release from the endothelium in both hypertensive and normotensive postmenopausal women, but that exercise training is not effective in improving oxidative stress markers.

\section{Conclusion}

Ten weeks of combined aerobic and resistance exercise training did not change salivary oxidative stress markers in either normotensive or hypertensive non-obese postmenopausal women but was able to increase salivary nitrite in both groups. Thus, recurrent exercise seems to be a safe strategy after menopause from the standpoint of oxidative stress, regardless of the presence of hypertension.

\section{Acknowledgments}

This work was supported by the [Fundação de Amparo à Pesquisa do Estado de Minas Gerais- FAPEMIG] under Grant [APQ-00750-14]; the [Conselho Nacional de Desenvolvimento Científico e Tecnológico - CNPq] under Grant [456443/2014-2]; and [794078/2013]. Furthermore, this study was financed in part by the [Coordenação de Aperfeiçoamento de Pessoal de Nível Superior - Brasil (CAPES)] - Finance Code 001. 


\section{Conflicts of interest}

No potential conflicts of interest were declared.

\section{References}

1. Takahashi TA, Johnson KM. Menopause. Med Clin North Am. 2015;99(3):521-34. doi

2. Knowlton AA, Korzick DH. Estrogen and the female heart. Mol Cell Endocrinol. 2014;389(1-2):31-9. doi

3. Virdis A, Taddei. S. Endothelial aging and gender. Maturitas. 2012;71(4):326-30. doi

4. Lagranha CJ, Silva TLA, Silva SCA, Braz GRF, da Silva AI, Fernandes MP, et al. Protective effects of estrogen against cardiovascular disease mediated via oxidative stress in the brain. Life Sci. 2018;192:190-8. doi

5. Di Giosia P, Giorgini P, Stamerra CA, Petrarca M, Ferri C, Sahebkar A. Gender differences in epidemiology, pathophysiology, and treatment of hypertension. Curr Atheroscler Rep. 2018;20(3):13. doi

6. Sies H, Berndt C, Jones DP. Oxidative stress. Annu Rev Biochem. 2017;86(1):715-48. doi

7. Bielli A, Scioli MG, Mazzaglia D, Doldo E, Orlandi A. Antioxidants and vascular health. Life Sci. 2015;143:20916. doi

8. Burleigh MC, Liddle L, Monaghan C, Muggeridge DJ, Sculthorpe N, Butcher JP, et al. Salivary nitrite production is elevated in individuals with a higher abundance of oral nitrate-reducing bacteria. Free Radic Biol Med. 2018;120:80-8. doi

9. Lundberg JO, Gladwin MT, Weitzberg E. Strategies to increase nitric oxide signalling in cardiovascular disease. Nat Rev. 2015;14(9):623-41. doi

10. Cavas L, Arpinar P, Yurdakoc K. Possible interactions between antioxidant enzymes and free sialic acids in saliva: a preliminary study on elite Judoists. Int J Sports Med. 2005;26(10):832-5. doi

11. Schiffrin EL. Vascular remodeling in hypertension: Mechanisms and treatment. Hypertension. 2011;59:367-74. doi

12. Ashor AW, Lara J, Siervo M, Celis-Morales C, Oggioni C, Jakovljevic DG, et al. Exercise modalities and endothelial function: a systematic review and dose-response meta-analysis of randomized controlled trials. Sports Med. 2015;45 (2):279-96. doi

13. de Sousa CV, Sales MM, Rosa TS, Lewis JE, de Andrade RV, Simões HG. The antioxidant effect of exercise: a systematic review and meta-analysis. Sport Med. 2017;47 (2):277-93. doi

14. Mancia G, Fagard R, Narkiewicz K, Redon J, Zanchetti A, Böhm M, et al. 2013 ESH/ESC guidelines for the management of arterial hypertension: the task force for the management of arterial hypertension of the European Society of Hypertension (ESH) and the European Society of Cardiology (ESC). Eur Heart J. 2013;34(28):2159-219. doi

15. Pescatello LS, MacDonald HV, Lamberti L, Johnson BT. Exercise for hypertension: a prescription update integrating existing recommendations with emerging research. Curr Hypertens Rep. 2015;17(11):87. doi
16. Cornelissen VA, Smart NA. Exercise training for blood pressure: a systematic review and meta-analysis. J Am Heart Assoc. 2013;2(1):e004473. doi

17. Larsen MK, Matchkov VV. Hypertension and physical exercise: the role of oxidative stress. Medicina. 2016;52 (1):19-27. doi

18. Dekleva M, Lazic JS, Arandjelovic A, Mazic S. Beneficial and harmful effects of exercise in hypertensive patients: the role of oxidative stress. Hypertens Res. 2017;40(1):15-20. doi

19. Matsudo S, Araujo T, Matsudo V, Andrade D, Andrade E, Oliveira LC, et al. International Physical Activity Questionnaire (IPAQ): study of validity and reliability in Brazil. Rev Bras Atividade Física e Saúde. 2001;6(2):5-18. doi

20. Puga GM, Novais IP, Katsanos C, Zanesco A. Combined effects of aerobic exercise and 1-arginine ingestion on blood pressure in normotensive postmenopausal women: a crossover study. Life Sci. 2016;151:323-9. doi

21. Wasserman K. The anaerobic threshold measurement to evaluate exercise performance. Am Rev Respir Dis. 1984;129:35-40. doi

22. Kraemer WJ, Fry A. Strength training: development and evaluation of methodology. Physiol Asses of Hum Fitness. 1995;115-38. doi

23. Souza AV, Giolo JS, Teixeira RR, Vilela DD, Peixoto LG, Justino AB, et al. Salivary and plasmatic antioxidant profile following continuous, resistance, and high-intensity interval exercise: preliminary study. Oxid Med Cell Longev. 2019; 2019:5425021. doi

24. Vilela DD, Peixoto LG, Teixeira RR, Baptista NB, Caixeta $\mathrm{DC}$, de Souza AV, et al. The role of metformin in controlling oxidative stress in muscle of diabetic rats. Oxid Med Cell Longev. 2016;2016:6978625. doi

25. Moorcroft MJ, Davis J, Compton RG. Detection and determination of nitrate and nitrite: a review. Talanta. 2001;54 (5):785-803. doi

26. Son WM, Sung KD, Cho JM, Park SY. Combined exercise reduces arterial stiffness, blood pressure, and blood markers for cardiovascular risk in postmenopausal women with hypertension. Menopause. 2017;24(3):262-8. doi

27. Sharman JE, La Gerche A, Coombes JS. Exercise and cardiovascular risk in patients with hypertension. Am J Hypertens. 2015;28(2):147-58. doi

28. Pouvreau C, Dayre A, Butkowski EG, de Jong B, Jelinek HF. Inflammation and oxidative stress markers in diabetes and hypertension. J Inflamm Res. 2018;11:61-8. doi

29. Araujo M, Wilcox CS. Oxidative stress in hypertension: role of the kidney. Antioxid Redox Signal. 2014;20(1):74-101. doi

30. Mariano IM, Dechichi JGC, Matias LAS, Rodrigues MDL, Batista JP, de Souza TCF, et al. Ambulatory blood pressure variability and combined exercise training: comparison between hypertensive and normotensive postmenopausal women. Blood Press Monit. 2020;25(6):338-45. doi

31. Dantas FFO, Brasileiro-Santos MDS, Batista RMF, Do Nascimento LS, Castellano LRC, Ritti-Dias RM, et al. Effect of strength training on oxidative stress and the correlation of the same with forearm vasodilatation and blood pressure of hypertensive elderly women: a randomized clinical trial. PLoS One. 2016;11(8):1-19. doi 
32. Peters PG, Alessio HM, Hagerman AE, Ashton T, Nagy S, Wiley RL. Short-term isometric exercise reduces systolic blood pressure in hypertensive adults: possible role of reactive oxygen species. Int J Cardiol. 2006;110(2):199-205. doi

33. Feairheller DL, Brown MD, Park J, Brinkley TE, Basu S, Hagberg JM, et al. Exercise training, NADPH oxidase p22phox gene polymorphisms, and hypertension. Med Sci Sports Exerc. 2009;41(7):1421-8. doi

34. Jarrete AP, Novais IP, Nunes HA, Puga GM, Delbin MA, Zanesco A. Influence of aerobic exercise training on cardiovascular and endocrine-inflammatory biomarkers in hypertensive postmenopausal women. J Clin Transl Endocrinol. 2014;1(3):108-14. doi

35. Oliveira VND, Bessa A, Jorge MLMP, Oliveira RJDS, de Mello MT, De Agostini GG, et al. The effect of different training programs on antioxidant status, oxidative stress, and metabolic control in type 2 diabetes. Appl Physiol Nutr Metab. 2012;37(2):334-44. doi

36. Giolo JS, Costa JG, da Cunha-Junior JP, Pajuaba ACAM, Taketomi EA, de Souza AV, et al. The effects of isoflavone supplementation plus combined exercise on lipid levels, and inflammatory and oxidative stress markers in postmenopausal women. Nutrients. 2018;10(4):1-11. doi

37. Sousa ECD, Abrahin O, Ferreira ALL, Rodrigues RP, Alves EAC, Vieira RP. Resistance training alone reduces systolic and diastolic blood pressure in prehypertensive and hypertensive individuals: a meta-analysis. Hypertens Res. 2017; 40(11):927-931. doi

38. Tanaka M, Umemoto S, Kawahara S, Kubo M, Itoh S, Umeji K, et al. Angiotensin II type 1 receptor antagonist and angiotensin-converting enzyme inhibitor altered the activa- tion of $\mathrm{Cu} / \mathrm{Zn}$-containing superoxide dismutase in the heart of stroke-prone spontaneously hypertensive rats. Hypertens Res. 2005;28(1):67-77. doi

39. Hermann M, Flammer A, Lscher TF. Nitric oxide in hypertension. J Clin Hypertens. 2006;8:17-29. doi

40. Castelao JE, Gago-Dominguez M. Risk factors for cardiovascular disease in women: relationship to lipid peroxidation and oxidative stress. Med Hypotheses. 2008;71(1):3944. doi

41. Weston KS, Wisløff U, Coombes JS. High-intensity interval training in patients with lifestyle-induced cardiometabolic disease: a systematic review and meta-analysis. Br J Sports Med. 2014;48(16):1227-34. doi

\section{Corresponding author}

Guilherme Morais Puga. Universidade Federal de Uberlândia, Faculdade de Educação Física. Rua Benjamin Constant 1286, Nossa Senhora Aparecida, 38400-678 Uberlândia, MG, Brazil. E-mail: gmpuga@gmail.com

Manuscript received on July 20, 2021

Manuscript accepted on October 18, 2021

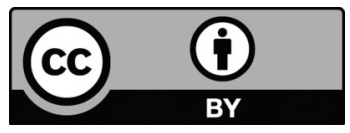

Motriz. The Journal of Physical Education. UNESP. Rio Claro, SP, Brazil - eISSN: 1980-6574 - under a license Creative Commons - Version 4.0 